\title{
BMJ Open Orthopaedic medical examination for young amateur athletes: a repeated cross-sectional study from 2014 to 2018
}

\author{
Takuji Yokoe (D) , Takuya Tajima, Nami Yamaguchi, Makoto Nagasawa, \\ Tomomi Ota, Yudai Morita, Etsuo Chosa
}

To cite: Yokoe T, Tajima T, Yamaguchi N, et al. Orthopaedic medical examination for young amateur athletes: a repeated cross-sectional study from 2014 to 2018. BMJ Open 2021;11:e042188. doi:10.1136/ bmjopen-2020-042188

- Prepublication history for this paper is available online. To view these files, please visit the journal online (http://dx.doi org/10.1136/bmjopen-2020042188).

Received 30 June 2020 Revised 05 December 2020 Accepted 31 December 2020

Check for updates

(C) Author(s) (or their employer(s)) 2021. Re-use permitted under CC BY-NC. No commercial re-use. See rights and permissions. Published by BMJ.

Division of Orthopaedic Surgery, Department of Medicine of Sensory and Motor Organs, Faculty of Medicine, University of Miyazaki, Miyazaki, Japan

Correspondence to

Dr Takuji Yokoe;

yokoetakuji@gmail.com

\section{ABSTRACT}

Objectives Medical examinations for adult elite athletes are performed all over the world, however, no studies in the relevant English literature have reported on orthopaedic medical examinations for young amateur athletes. The purpose of this study was to report the results of orthopaedic medical examinations of the spine and lower extremities in young amateur athletes.

Methods This repeated cross-sectional study from 2014 to 2018 included a total of 323 young amateur athletes (age, 12-18 years) who were active in one of the following four sports: boxing, canoeing, weightlifting and track and field. The orthopaedic medical examination consisted of six assessments (physical examinations, the generalised joint laxity, muscle and joint tightness, static alignment and muscle volume of the lower extremities and the medial Iongitudinal arch of the foot). Questions regarding pain in the spine and lower extremities were also performed. Results Among 323 young amateur athletes, 17 (5.3\%) had received orthopaedic treatment at the time of the medical examination, with spondylolysis being the most common cause (29.4\%, 5/17). Among 306 young athletes who had not received orthopaedic treatment, $61(19.9 \%)$ had at least one positive finding in physical examinations or had pain in the spine or lower extremities. Anterior drawer test of the ankle and Kemp test for the spine accounted for $34 \%$ and $28 \%$ of positive findings, respectively. Low back pain and knee pain accounted for $58 \%$ and $16 \%$ of pain, respectively.

Conclusions The present study showed that approximately one-fifth of young amateur athletes who had not received orthopaedic treatment had pain in the spine and lower extremities and positive findings in physical examinations that may require orthopaedic treatments. In addition to the early detection of injuries, orthopaedic medical examinations for young amateur athletes provide an opportunity to educate such athletes.

\section{INTRODUCTION}

The number of school-aged children (age, 5-18 years) who participate in sports has been increasing and is estimated to be approximately 40 million in the USA. ${ }^{12}$ These young athletes will sustain about 4 million sport-related injuries annually and will require 2.6 million emergency department visits. ${ }^{2-4}$ Pain affecting the low back or lower

\section{Strengths and limitations of this study}

- This study presents the results of orthopaedic medical examinations for 323 young amateur athletes.

- The orthopaedic medical examination in this study was originally developed in our country.

- The examination consists of six categories (physical examinations of the spine and lower extremities, generalised joint laxity, muscle and joint tightness, static alignment, muscle volume of the lower extremities and medial longitudinal arch of the foot).

- This study evaluated four sports activities (boxing, canoeing, weightlifting and track and field), which makes it impossible to describe the results of young athletes who participate in other sports activities.

- It remains unclear whether the procedures or frequency of the orthopaedic medical examinations in this study are valid because of no previous studies reporting orthopaedic medical examinations for young amateur athletes.

extremities is a common report among young athletes. The incidence of low back pain (LBP) among young athletes has been reported in several articles, ${ }^{5-7}$ and Micheli and Wood reported that $47 \%$ of young athletes with LBP had spondylolysis. ${ }^{8}$ It has also been reported that LBP is more prevalent in sports requiring high spinal loads. ${ }^{9-11}$ Several studies have reported that the foot morphology, such as low and high arch, made the athlete's foot more prone to injury. ${ }^{12}{ }^{13}$ Excessive foot pronation has been identified as a risk factor for injuries in football and in the development of medial tibial stress syndrome. ${ }^{14}$ The knee is the most frequently injured joint in young athletes. ${ }^{16}$ Kujala et al reported that the incidence of knee injuries was $20.8 \%$ in soccer players and $13.1 \%$ in runners. ${ }^{17}$ Hall et al found that early sport specialisation in female adolescents increased the relative risk of anterior knee pain, Osgood Schlatter disease and Sliding Larsen Johansson disease in comparison to multiple sports activities. ${ }^{18}$ 
According to the International Olympic Committee consensus statement on young athletic development, it is documented that designing youth athlete development programmes to mitigate the risk of overuse injuries, performing evidence-based injury prevention programmes and developing knowledge translation strategies that will promote health in young athletes are recommended. ${ }^{19} \mathrm{In}$ order to protect young athletes from acute and overuse injuries, multidirectional approaches are required. For example, many researchers have demonstrated the efficacy of prevention programmes such as neuromuscular training for anterior cruciate ligament (ACL) injury. ${ }^{20-22}$ In addition to prevention programmes, early detection of these reports and symptoms is extremely important for enabling treatments to be initiated as early as possible and to allow young athletes to return to their respective sports without severe complications. The orthopaedic medical examination (orthopaedic screening) for young athletes may be valuable, not only for the early detection of injuries in young athletes but also for evaluating physical characteristics and educating athletes, their parents and coaches. It is important to identify individuals who have some injuries and disorders, but who have not taken orthopaedic treatments. There is a lack of evidence regarding how many young athletes-with injuries or conditions that should be managed by orthopaedic treatments-keep participating in their sports activities. In the majority of countries, medical examinations are usually performed for elite adult athletes and are not performed for young athletes, especially for amateur athletes. To the best of our knowledge, no studies in the relevant English literature have reported on orthopaedic medical examinations for the screening of young amateur athletes. The purpose of the present study was to report the results of orthopaedic medical examinations for young amateur athletes.

\section{MATERIALS AND METHODS}

\section{Patient and public involvement}

Patients or the public were not involved in the design of the study.

\section{Study design}

The orthopaedic medical examinations were annually performed in a single institute from 2014 to 2018. Informed assent and consent were obtained from the participants and their parents before the enrolment of this study.

\section{Participants}

All the study population included young athletes (junior high school or high school students) who were selected in the study area for the annual national championship tournament in Japan. Among these young athletes, young athletes who participated in one of four sports activities; boxing, canoeing, weightlifting and track and field, were included in this study. The included sports activities were determined after a discussion with the sports association in the study area, due to the limited cost and number of available medical staff. The mean duration of practising each sport was 5.0 years (range, 4-6 years). The mean frequency and duration of each practice/week were 5.3 times (range, 5-6 times) and 3.8 hours (range, 3-4 hours), respectively.

\section{Procedures}

All of the enrolled athletes were assessed without information regarding previous and present injuries or symptoms affecting the spine and lower extremities. The participants were questioned as to whether they had seen an orthopaedic doctor within the last 4 weeks and whether they had pain and symptoms in the spine and lower extremities at the time of medical examinations. The pain and symptoms that had lasted for more than 4 weeks were considered.

Orthopaedic medical examinations were performed for all of the included individuals by a total of 10 senior orthopaedic surgeons and 20 physical therapists who were specialised in sports medicine. In order to assess the individuals in a reliable and reproducible manner, the details of all examinations were documented before the initiation of this study. All medical providers performed medical examinations based on these reports throughout the study. The orthopaedic medical examination in this study was divided into six categories (table 1): category 1 , physical examinations of the spine, knee and ankle joints; category 2, assessment of the generalised joint laxity (GJL); category 3, assessment of the muscle and joint tightness of the lower extremities; category 4, assessment of the static alignment of the lower extremities; category 5 , assessment of the muscle volume of the lower extremities; category 6 , assessment of the height of the medial longitudinal arch of the foot. Category 1 was performed by orthopaedic surgeons, and other categories (categories 2-6) were performed by physical therapists. The procedures of orthopaedic medical examinations were introduced by Nakajima ${ }^{23}$ and were modified by the authors in this study.

\section{Category 1}

Physical examinations included Kemp test for spine injuries (figure 1), ${ }^{24}$ six assessments for knee injuries (lateral stress test of the patella, Lachman test, posterior drawer test, McMurray test, varus and valgus stress test) and two assessments for ankle injuries (anterior drawer test and inversion stress test). When the young athlete reported of some pain or disorders that could not be assessed by the above physical examinations, additional physical examinations were performed to evaluate them.

\section{Category 2}

The Japanese assessment method for the GJL, which was introduced by Simon $e a^{16}$ and which is commonly used to evaluate GJL in Japan, was used in the present study because other methods for the assessment of GJL, 
Table 1 Summary of the orthopaedic medical examinations in this study

\begin{tabular}{|c|c|}
\hline Assessment (six categories) & Methods \\
\hline \multicolumn{2}{|l|}{ 1. Physical examinations } \\
\hline Spine & Kemp test \\
\hline \multirow[t]{6}{*}{ Knee joint } & Lateral stress test of the patella \\
\hline & Lachman test \\
\hline & Posterior drawer test \\
\hline & McMurray test \\
\hline & Varus stress test \\
\hline & Valgus stress test \\
\hline \multirow[t]{2}{*}{ Ankle joint } & Anterior drawer test \\
\hline & Inversion stress test \\
\hline 2. Generalised joint laxity & Nakajima criteria \\
\hline \multirow{5}{*}{$\begin{array}{l}\text { 3. Muscle and joint tightness } \\
\text { of the lower extremities }\end{array}$} & Finger floor distance \\
\hline & Passive straight leg raising test \\
\hline & Thomas test \\
\hline & Ely's test \\
\hline & Dorsiflexion of the ankle joint \\
\hline \multirow{2}{*}{$\begin{array}{l}\text { 4. Static alignment of the } \\
\text { lower extremities }\end{array}$} & Quadriceps (Q) angle \\
\hline & Leg-heel angle \\
\hline \multirow[t]{2}{*}{$\begin{array}{l}\text { 5. Muscle volume of the lower } \\
\text { extremities }\end{array}$} & Circumferencial length of the thigh \\
\hline & Circumferencial length of the calf \\
\hline $\begin{array}{l}\text { 6. The height of medial } \\
\text { longitudinal arch of the foot }\end{array}$ & $\begin{array}{l}\text { The height from the tip of the } \\
\text { navicular bone to the ground surface }\end{array}$ \\
\hline
\end{tabular}

including Beighton criteria, ${ }^{25}$ cannot evaluate the spine, hip and ankle joints. This assessment method evaluates six bilateral joints (shoulder, elbow, wrist, hip, knee and ankle joint) and the spine (figure 2). When one of the 12 joints meets the criteria, a score of 0.5 points is given; when the spine meets the criteria, a score of 1.0 point is given. Total scores range from 0 to 7 points, with a higher score indicating the presence of GJL.

\section{Category 3}

Muscle and joint tightness of the lower extremities was assessed by finger floor distance, ${ }^{26}$ straight leg raising (SLR) test, ${ }^{27}$ Thomas test ${ }^{28}$ and Ely's test ${ }^{29}$ and assessment of the active dorsiflexion of the ankle joint in the supine position with a goniometer (figure 3).

\section{Category 4}

The quadriceps angle $(Q$ angle) was examined in the supine position with a goniometer to measure the line connecting the anterior superior iliac spine and the midpoint of patella intersecting with the line connecting the tibial tubercle to the midpoint of the patella. ${ }^{30}$ The leg-heel angle was evaluated from behind the individual in a standing position and was classified as supination, neutral and pronation.
A

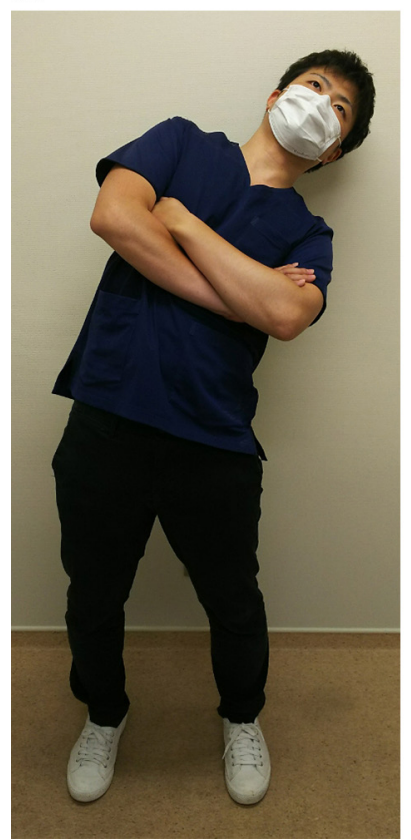

B

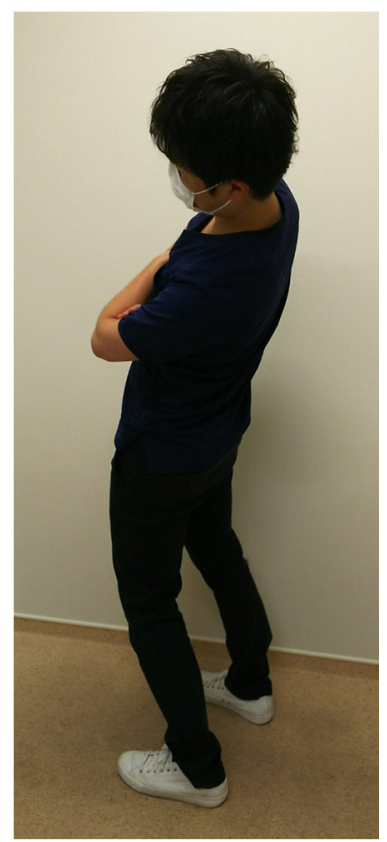

Figure 1 Left-sided Kemp test. (A) Front view and (B) lateral view. Lateral flexion and extension of the trunk is performed with the subject standing in a bipedal stance. The test is positive when the low back pain is present. This test is performed on both sides.

\section{Category 5}

The muscle volume of the lower extremities was assessed with the subject standing in a relaxed bipedal stance, by the circumferential length of the thigh at $10 \mathrm{~cm}$ above the proximal tip of the patella and by the maximum circumferential length of the calf.

\section{Category 6}

The medial longitudinal arch of the foot was assessed by the height from the tip of the navicular tubercle to the ground surface with the subject standing in a relaxed bipedal stance. ${ }^{31}$ The tip of the navicular tuberosity was palpated and marked with a marking pen. A ruler was used to measure the height of the navicular tuberosity from the ground (figure 4). Low arch was defined as a height shorter than $15 \mathrm{~mm}$ in this study because Roth et al reported that the height of the navicular bone from the floor was in proportion with that of the longitudinal arch of the foot, and the mean navicular height in patients with flexible flat foot was $15.67 \pm 4.3 \mathrm{~mm} .^{32}$

\section{Statistical analysis}

All data collected in this study were recorded and analysed using SPSS software (V.21.0, SPSS, Chicago, Illinois, USA). Descriptive statistics was reported as percentage or mean \pm SD. All examinations resulted were stratified by sport.

\section{RESULTS}

A total of 323 young athletes (age, 12-18 years) were included in the present study. The mean age was $15.9 \pm 1.1$ years, and 218 athletes were men $(67.5 \%)$. The 


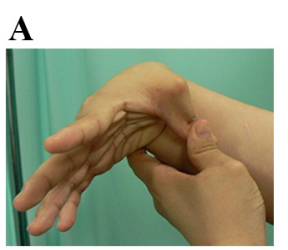

B

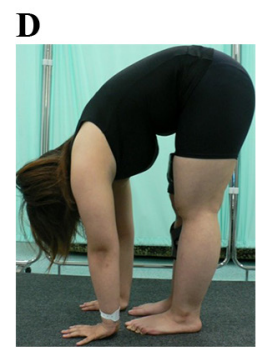

E

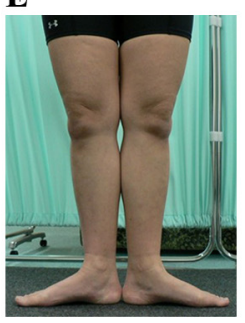

C
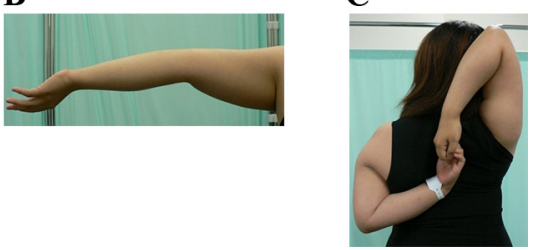

F

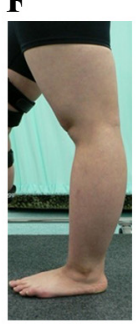

G

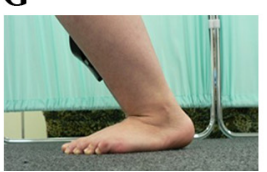

Figure 2 The Nakajima criteria for generalised joint laxity. (A) Passive opposition of both thumbs to volar aspects of ipsilateral forearms. (B) Hyperextension of both elbows beyond $15^{\circ}$. (C) Crossing fingers behind the back. (D) Forward flexion of the trunk with the knees fully extended and palms resting on the floor. (E) External rotation of both hips beyond $90^{\circ}$. (F) Hyperextension of both knees beyond $10^{\circ}$.

(G) Dorsiflexion of both ankles beyond $45^{\circ}$. Tests other than

(C) and (D) are bilateral. The patient receives a score for each individual joint that is determined based on the evaluation of these items (score 0-7).

participants included 110 boxers (men/women, 97/13), 67 canoeists (men/women, 45/22), 61 weightlifters (men/women, 40/21) and 85 track and field players (men/women, 36/49). The characteristics of the young athletes are summarised in table 2 .

\section{Young athletes who had received orthopaedic treatment}

Among 323 young athletes, $17(5.3 \%)$ had received an orthopaedic treatment at the time of the orthopaedic medical examination; the details are summarised in figure 5. The percentage of individuals in the weightlifting, track and field, boxing and canoeing groups who had required orthopaedic treatments was $9.8 \%(6 / 61)$, $7.1 \%(6 / 85), 3.6 \%(4 / 110)$ and $1.5 \%(1 / 67)$, respectively. Spinal and lower extremity pathologies were the reason for orthopaedic treatment in $35.3 \%(6 / 17)$ and $41.2 \%(7 / 17)$ of the cases, respectively. Spondylolysis was the most common reason for seeking orthopaedic treatment $(5 / 17,29.4 \%)$, followed by recurrent ankle sprain $(2 / 17,11.8 \%)$.

\section{The prevalence of pain and results of category 1}

The prevalence of pain in the spine and lower extremities and the results of the physical examinations (excluding the 17 athletes who had received orthopaedic treatment at the time of medical examination) are summarised in

A

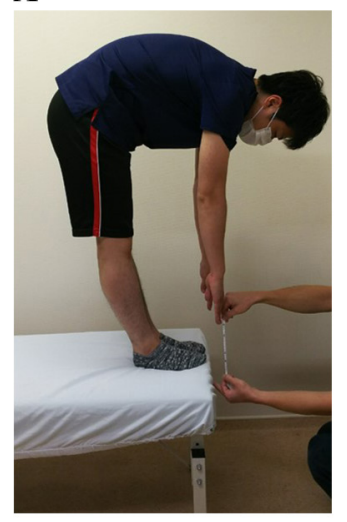

B

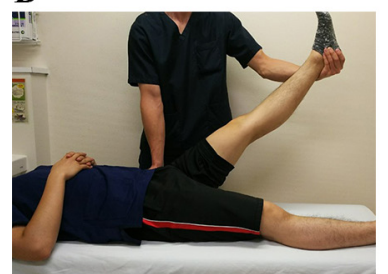

C

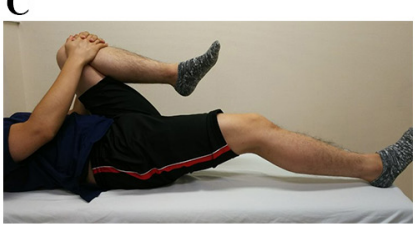

D

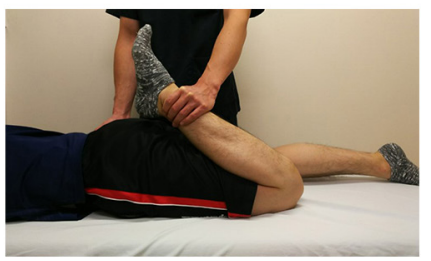

$\mathbf{E}$

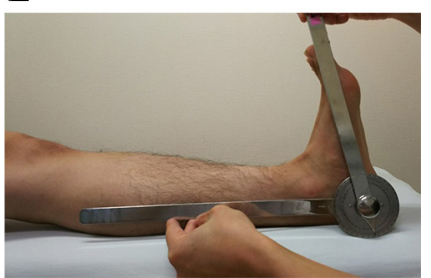

Figure 3 The assessment of muscle and joint tightness of the lower extremities. (A) Finger floor distance. The test is performed with the subject standing straight, feet together. The subject is instructed to bend forward as far as possible, with their knees, arms and fingers fully extended. The vertical distance between the tip of the middle finger and the floor is measured with a ruler. In the present study, the test was positive when the middle finger did not touch the floor. (B) Straight leg raising test. The patient's leg is lifted by the posterior ankle, while maintaining the knee joint fully extended, until the subject complains of pain or tightness in the back of the leg. (C) Thomas test. The test is performed with the subject in the supine position. The ipsilateral limb is gradually flexed to eliminate lumbar lordosis. When flexion of the contralateral hip is present, the test is positive. (D) Ely's test. The ipsilateral knee joint is gradually flexed with the subject in the prone position. The test is positive when the patient's hip flexes up from the floor. (E) Assessment of the dorsiflexion of the ankle joint. The evaluation was performed with the subject in the supine position using a goniometer.

figure 6. Among 306 young athletes, 61 (19.9\%) had pain in the spine and/or the lower extremities or had positive findings in the physical examinations. Of 50 (16.3\%) had at least one positive findings of physical examinations and $50(16.3 \%)$ had spinal and/or lower extremity pain. The percentage of individuals in weightlifting, track and field, canoeing and boxing was $32.7 \%$ (18/55), 30.4\% $(24 / 79), 16.7 \%(11 / 66)$ and $7.5 \%(8 / 106)$, respectively. The origin of pain was the low back in $29(58 \%)$, followed by the knee in $8(16 \%)$ and the ankle in $5(10 \%)$. Among 50 who had positive findings in physical examinations, 17 (34\%) had positive findings in anterior drawer test of the ankle, 14 (28\%) had in Kemp test, 11 (22\%) had in inversion stress test of the ankle and $4(8 \%)$ had in McMurray test. 


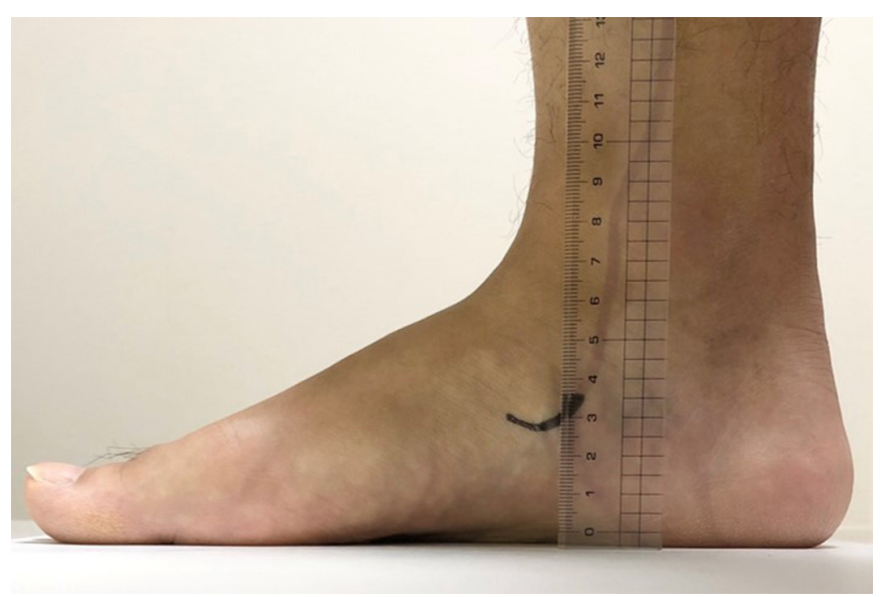

Figure 4 Photograph showing the measurement of the medial longitudinal arch of the foot. The height from the tip of the navicular tubercle to the ground surface was measured with a ruler, and defined as low arch when it was $<15 \mathrm{~mm}$.

\section{The results of categories 2-6}

The results of categories 2-6 are shown in table 3 .

\section{DISCUSSION}

The present study demonstrated that almost a fifth (19.9\%) of young athletes, who had not previously been treated by orthopaedic doctors, had spinal and/or lower extremity pain and/or had positive findings in physical examinations of the spine and lower extremities that may need a management by orthopaedic doctors. Medical check-ups are generally performed for elite adult athletes in most countries, ${ }^{33} 34$ and many studies have reported on cardiac screening with electrocardiography. ${ }^{35} 36$ Cardiac screening has been recommended as preparticipation examination for both top athletes and amateur athletes to identify fatal cardiac pathologies. ${ }^{37} \mathrm{~A}$ number of studies have reported the epidemiology of the incidence of pain and risk factors for some sports-related injuries

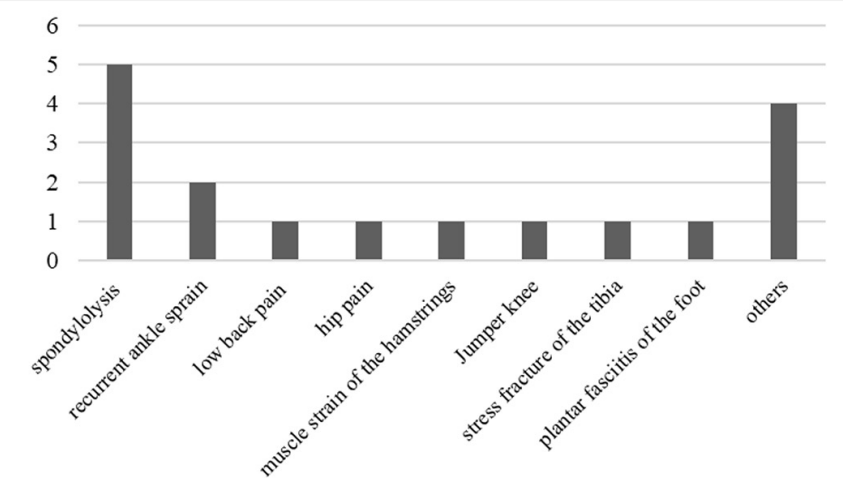

Figure 5 The reasons why young athletes who had received orthopaedic treatments at the time of the medical examination $(n=17)$.

in young amateur athletes. ${ }^{38-40}$ However, to the best of our knowledge, no studies in the relevant English literature have reported on the implementation of orthopaedic medical examinations (orthopaedic screening) for young amateur athletes. Participating in sports activities lead to health promotion in young generations, including a positive body image, a better cardiorespiratory function and an improved sense of well-being. ${ }^{414}$ However, most participants, their parents and coaches tend to seek improved skills and victory in competitions, which requires overtraining and which has the potential to cause both acute and chronic injuries. In addition to physiological overstress, young athletes are increasingly exposed to psychological overload from excessive and unrealistic expectations by their parents/coaches ${ }^{43}$ which may result in a risk of concealing pain and symptoms. In order to detect and treat young athletes with any injury or disease as soon as possible, orthopaedic medical examinations may be an effective intervention. It has been recommended that intense training in a single sport should be delayed until late adolescence to

Table 2 Characteristics of young athletes

(A) Male athletes

$\begin{array}{lcccc}\text { Variable } & \text { Boxers }(n=97) & \text { Canoeists }(n=45) & \text { Weightlifters }(n=40) & \text { Track and field athletes }(n=36) \\ \text { Age, years } & 15.8 \pm 1.5 & 15.9 \pm 0.7 & 16.1 \pm 0.8 & 16.2 \pm 0.8 \\ \text { Height, } \mathrm{cm} & 165.3 \pm 9.1 & 169.5 \pm 5.1 & 166.5 \pm 5.7 & 175.2 \pm 6.5 \\ \text { Weight, } \mathrm{kg} & 53.9 \pm 9.4 & 62.3 \pm 6.7 & 70.3 \pm 11.7 & 72.5 \pm 17.8 \\ \text { BMI } & 19.6 \pm 1.8 & 21.7 \pm 2.1 & 25.3 \pm 4.6 & 23.6 \pm 5.0\end{array}$

(B) Female athletes

\begin{tabular}{lcccc} 
Variable & Boxers $(n=13)$ & Canoeists $(n=22)$ & Weightlifters $(n=21)$ & Track and field athletes $(n=49)$ \\
Age, years & $15.9 \pm 1.5$ & $16.1 \pm 0.7$ & $16.3 \pm 0.8$ & $16.1 \pm 0.9$ \\
Height, $\mathrm{cm}$ & $154.3 \pm 4.6$ & $155.5 \pm 5.0$ & $154.9 \pm 3.9$ & $162 \pm 4.6$ \\
Weight, $\mathrm{kg}$ & $47.8 \pm 5.3$ & $53.5 \pm 6.1$ & $57.6 \pm 9.2$ & $55.0 \pm 8.4$ \\
BMI & $19.3 \pm 3.2$ & $22.1 \pm 1.9$ & $23.9 \pm 3.0$ & $21.0 \pm 3.1$ \\
\hline
\end{tabular}

Data presented as mean \pm SD unless otherwise indicated.

BMI, body mass index. 
A

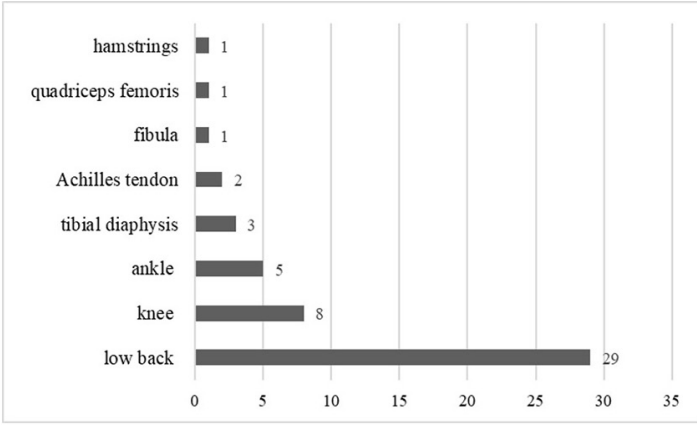

B

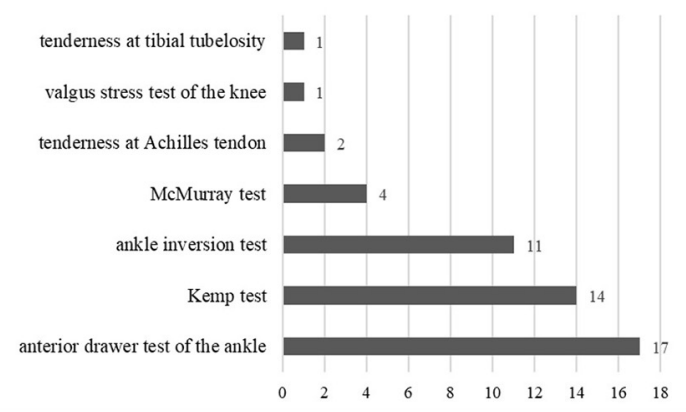

Figure 6 (A) Details of pain identified at the orthopaedic medical examination for young athletes $(n=50)$. (B) Details of positive findings of physical examinations for young athletes $(n=50)$.

minimise the risk of injury and psychological stress. ${ }^{44}$ However, youth sports specialisation in a single sport at the exclusion of other sports has been increasing, ${ }^{46}$ as the participants in the present study did. Several injury prevention programmes are demonstrated to reduce the incidence of sports-specific injuries, ${ }^{20-22} 47$ however, there is a lack of knowledge and corresponding behaviour among young athletes and their coaches with regards to these prevention strategies. After collecting and analysing the data of the medical examinations, we informed the young athletes and their patients/coaches of the results of the examinations to educate them and their parents. We believe that education after medical examinations will contribute to reducing the prevalence of joint-related pain and injuries in high-risk athlete who participate in a single sport. However, there are many issues that remain undecided in orthopaedic medical examinations for young athletes, including what kinds of assessments should be performed, the timing (off-season vs in-season) and frequency of the medical examinations, the level of young athletes who should undergo examinations and cost problems. No studies or protocols have answered these issues. Further study is needed to clarify these problems and to improve the quality of orthopaedic medical examinations.

The present study showed that spondylolysis (29.3\%) and recurrent ankle sprains $(11.8 \%)$ were the main reasons for young athletes to receive orthopaedic treatments. LBP accounted for $58 \%$ of the origins of the pain, and the anterior drawer test and Kemp test accounted for $62 \%$ of positive findings in physical examinations. It was reported that $7 \%$ of 12 -year olds and $53 \%$ of 18 -year olds had experienced at least one episode of LBP in their lifetime. ${ }^{48} \mathrm{LBP}$ is a particularly common symptom in competitive young athletes, with an estimated prevalence ranging from $1 \%$ to $30 \% .^{49}$ Spondylolysis is a major cause of LBP in young athletes, ${ }^{851}$ and Sakai $e t$ al reported that the bony healing rate after conservative treatment of spondylolysis in patients with early stage was $100 \%$, while it was $80 \%$ in patients with the progressive stage.$^{52}$ Orthopaedic medical examinations would enable physicians to detect young athletes with spondylolysis at an early stage, which may lead to favourable clinical outcomes after conservative treatment without residual complications. Acute ankle sprain has been reported to be the most common injury sustained by athletes, accounting for almost $40 \%$ of sports injuries. ${ }^{53}{ }^{54}$ If acute ankle sprains are not treated appropriately, $10 \%-20 \%$ lead to recurrent ankle sprains and chronic ankle instability. ${ }^{55}$ Recurrent ankle sprains are also prevalent in young athletes. ${ }^{56}{ }^{57}$ Previous studies reported that less than $64 \%$ of athletes did not seek medical treatment after an ankle sprain, ${ }^{58}{ }^{59}$ indicating ignorance and a lack of knowledge in relation to ankle sprain. Orthopaedic medical examinations will help to detect young athletes with recurrent ankle sprains and to instruct them to see an orthopaedic physician. This would lead to a reduction in the prevalence of chronic lateral ankle instability in young athletes.

Another interesting point of the present study was that orthopaedic medical examinations could evaluate physical characteristics and the pattern of injuries and symptoms in each sport. Due to the results of the present study, participants showed specific findings depending on the type of sport. Educating young athletes and their coaches about these characteristic findings in each sport would be a preventive strategy for sports-related injuries. Weightlifters tended to have relatively tight quadriceps and hamstrings in comparison to athletes in other sports activities, as was shown in the results of the Ely's test and the SLR test. Several studies described that LBP was most common in weightlifters. ${ }^{3460}$ Tight quadriceps and hamstrings are considered risk factors for $\mathrm{LBP},{ }^{61}{ }^{62}$ therefore weightlifters should be educated to improve tight quadriceps and hamstrings to prevent and improve LBP. Supinated foot and flat foot (pes planus) have been considered risk factors for overuse injuries of the lower extremities. ${ }^{63-65}$ One systematic review performed by Bromley et al reported that the most frequently injured areas in boxers were the head/face $(45.8 \%)$, wrist $(12 \%)$ and low back $(7.8 \%) .{ }^{66}$ Boxers tended to have a higher percentage of low medial longitudinal arch of the foot, supinated leg-heel angle in this study. As far as we know, there is no study evaluating the alignment and posture of the foot in boxers. Therefore, it was impossible to describe why boxers had higher prevalence of lower medial longitudinal arch of the foot and supinated leg-heel angle in this study. Further studies will therefore be required to evaluate the correlation between foot morphology and injuries in boxers because the medial longitudinal arch of 
Table 3 Results of the orthopaedic medical examinations (categories 2-6)

\begin{tabular}{|c|c|c|c|c|c|}
\hline Variable & $\begin{array}{l}\text { Total } \\
(n=323)\end{array}$ & $\begin{array}{l}\text { Boxers } \\
(n=110)\end{array}$ & $\begin{array}{l}\text { Canoeists } \\
(\mathrm{n}=67)\end{array}$ & $\begin{array}{l}\text { Weightlifters } \\
(n=61)\end{array}$ & $\begin{array}{l}\text { Track and field } \\
\text { athletes }(n=85)\end{array}$ \\
\hline GJL & $1.7 \pm 1.2$ & $1.8 \pm 1.2$ & $1.7 \pm 1.3$ & $1.5 \pm 1.0$ & $1.9 \pm 1.4$ \\
\hline FFD, n (\%) & $56(17.3)$ & 19 (17.3) & $16(23.9)$ & $12(19.7)$ & $9(10.6)$ \\
\hline $\operatorname{SLR}(\mathrm{R}){ }^{\circ}$ & $75.3 \pm 12.1$ & $78.9 \pm 10.7$ & $77.0 \pm 12.8$ & $69.3 \pm 13.7$ & $76.0 \pm 11.0$ \\
\hline $\operatorname{SLR}(\mathrm{L}),^{\circ}$ & $75.4 \pm 11.8$ & $78.2 \pm 8.8$ & $76.9 \pm 13.0$ & $69.9 \pm 14.2$ & $76.5 \pm 11.0$ \\
\hline Thomas test (R), n (\%) & $45(13.9)$ & 15 (13.6) & $9(13.4)$ & $6(9.8)$ & $15(17.6)$ \\
\hline Thomas test (L), $\mathrm{n}(\%)$ & $44(13.6)$ & $14(12.7)$ & $11(16.4)$ & $5(8.2)$ & $14(16.5)$ \\
\hline Ely's test (R), n (\%) & $85(26.3)$ & 19 (17.3) & $16(23.9)$ & $28(45.9)$ & $22(25.9)$ \\
\hline Ely's test (L), n (\%) & $75(23.2)$ & 19 (17.3) & $11(16.4)$ & $27(44.3)$ & $18(21.2)$ \\
\hline Dorsiflexion of the ankle joint (R), ${ }^{\circ}$ & $13.4 \pm 6.7$ & $14.7 \pm 7.8$ & $13.2 \pm 6.6$ & $11.8 \pm 6.2$ & $13.7 \pm 6.2$ \\
\hline Dorsiflexion of the ankle joint (L), ${ }^{\circ}$ & $12.5 \pm 6.1$ & $13.8 \pm 6.9$ & $13.1 \pm 5.5$ & $11.3 \pm 5.7$ & $11.7 \pm 6.3$ \\
\hline$Q$ angle $(\mathrm{R}){ }^{\circ}$ & $11.8 \pm 4.8$ & $10.2 \pm 4.7$ & $12.9 \pm 4.4$ & $11.9 \pm 4.5$ & $12.0 \pm 5.5$ \\
\hline Q angle (L), ${ }^{\circ}$ & $11.2 \pm 4.3$ & $10.5 \pm 4.5$ & $11.4 \pm 3.8$ & $11.7 \pm 3.7$ & $11.2 \pm 5.1$ \\
\hline Leg heel angle (R), $n(\%)$ pronation & $55(17.0)$ & $16(14.5)$ & $16(23.9)$ & $8(13.1)$ & $15(17.6)$ \\
\hline Supination & $52(16.1)$ & $29(26.4)$ & $6(9.0)$ & $6(9.8)$ & $11(12.9)$ \\
\hline Neutral & $216(66.9)$ & $65(59.1)$ & $45(67.2)$ & $47(77.0)$ & $59(69.4)$ \\
\hline Leg heel angle (L), $n(\%)$ pronation & $63(19.5)$ & $16(14.5)$ & $19(28.4)$ & $9(14.8)$ & $19(22.4)$ \\
\hline Supination & $53(16.4)$ & $29(26.4)$ & $6(9.0)$ & $6(9.8)$ & $12(14.1)$ \\
\hline Neutral & $210(65.0)$ & $65(59.1)$ & $42(62.9)$ & $46(75.4)$ & $57(67.1)$ \\
\hline Circumferencial length of the thigh $(\mathrm{R}), \mathrm{cm}$ & $46.3 \pm 3.4$ & $42.7 \pm 3.1$ & $45.6 \pm 2.5$ & $49.8 \pm 3.3$ & $47.1 \pm 4.5$ \\
\hline Circumferencial length of the thigh (L), $\mathrm{cm}$ & $46.5 \pm 3.5$ & $43.4 \pm 3.7$ & $45.6 \pm 2.5$ & $50.0 \pm 3.3$ & $46.9 \pm 4.4$ \\
\hline Circumferencial length of the calf $(\mathrm{R}), \mathrm{cm}$ & $35.7 \pm 2.6$ & $33.9 \pm 2.3$ & $35.0 \pm 1.9$ & $36.7 \pm 2.9$ & $37.3 \pm 3.3$ \\
\hline Circumferencial length of the calf $(\mathrm{L}), \mathrm{cm}$ & $35.6 \pm 2.6$ & $33.9 \pm 2.3$ & $35.0 \pm 1.9$ & $36.5 \pm 3.0$ & $37.1 \pm 3.2$ \\
\hline Low medial longitudinal arch of the foot (R), $n(\%)$ & $136(42.1)$ & $53(48.2)$ & $24(35.8)$ & $25(41.0)$ & $34(40.0)$ \\
\hline Low medial longitudinal arch of the foot (L), $n(\%)$ & $138(42.7)$ & $54(49.1)$ & $26(38.8)$ & $25(41.0)$ & $33(38.8)$ \\
\hline
\end{tabular}

Data presented as mean \pm SD unless otherwise indicated.

The value in FFD, Thomas test and Quadriceps hip-up test shows the number of patients with positive findings.

BMI, body mass index; FFD, finger floor distance; GJL, generalised joint laxity; L, left; R, right; SLR, straight leg raising.

the foot was assessed only as the navicular height, without the analysis of X-rays in the present study.

There were several limitations to the present study. First, the young amateur athletes enrolled in this study had high-level performance in their respective sports, therefore the generalisation of the results of this study to all young amateur athletes may not be appropriate. Second, the study only assessed young athletes in four sports activities (boxing, canoeing, weightlifting and track and field), therefore, we could not evaluate young athletes who participated in other sports activities. Third, orthopaedic medical examinations in this study were originally developed in our country and it remains unclear whether the system or the assessment of the orthopaedic medical examinations in this study was appropriate. Fourth, plain radiographs, such as lateral weight-bearing radiographs, were not taken to evaluate flat foot. The orthopaedic medical examination is a screening test, therefore, performing X-rays for all individuals would be an excessive procedure with exposure to radiation and would not be cost-effective. Palpation and measurement of the height of the navicular tuberosity have been shown to provide valid information regarding the structure of the medial longitudinal arch, ${ }^{67}$ therefore, this method may be appropriate as a screening test for the flat foot. Despite these limitations, the present study showed the significance of orthopaedic medical examinations for young amateur athletes in order to detect their injuries and pain as soon as possible and to educate young athletes, their parents and coaches.

\section{CONCLUSIONS}

We herein first reported the results of orthopaedic medical examinations (screening) of a total of 323 young amateur athletes (boxers, canoeists, weightlifters and track and field athletes). Among these athletes, 5.3\% had received orthopaedic treatment, and $19.9 \%$ of the young athletes, who had not received orthopaedic treatment, were considered to require management by orthopaedic 
doctors. In addition to facilitating the early detection and treatment of acute and chronic injuries in young amateur athletes, the performance of orthopaedic medical examinations provides an opportunity to educate such athletes and maintain their well-being and would be therefore an important screening method.

Contributors TY collected data. TY and TT mainly drafted the manuscript, and NY, MN, TO, YM and EC supervised it. All authors performed orthopaedic medical examinations in this study. All authors had complete access to all data used in this study and take responsibility for its accuracy. All authors have read and approved the final manuscript.

Funding The authors have not declared a specific grant for this research from any funding agency in the public, commercial or not-for-profit sectors.

Competing interests None declared.

Patient and public involvement Patients and/or the public were involved in the design, or conduct, or reporting, or dissemination plans of this research. Refer to the Methods section for further details.

\section{Patient consent for publication Obtained.}

Ethics approval Ethical approval of this study was obtained from the institutional review board at Miyazaki University Graduate School of Medicine (Approval number 2015-101).

Provenance and peer review Not commissioned; externally peer reviewed.

Data availability statement All data relevant to the study are included in the article or uploaded as supplementary information. Data are available upon reasonable request.

Open access This is an open access article distributed in accordance with the Creative Commons Attribution Non Commercial (CC BY-NC 4.0) license, which permits others to distribute, remix, adapt, build upon this work non-commercially, and license their derivative works on different terms, provided the original work is properly cited, appropriate credit is given, any changes made indicated, and the use is non-commercial. See: http://creativecommons.org/licenses/by-nc/4.0/.

\section{ORCID iD}

Takuji Yokoe http://orcid.org/0000-0003-4117-2442

\section{REFERENCES}

1 McGuine T. Sports injuries in high school athletes: a review of injury-risk and injury-prevention research. Clin J Sport Med 2006;16:488-99.

2 Adirim TA, Cheng TL. Overview of injuries in the young athlete. Sports Med 2003;33:75-81.

3 Knowles SB, Marshall SW, Bowling JM, et al. A prospective study of injury incidence among North Carolina high school athletes. Am J Epidemiol 2006;164:1209-21.

4 Burt CW, Overpeck MD. Emergency visits for sports-related injuries. Ann Emerg Med 2001;37:301-8.

5 Kujala UM, Taimela S, Erkintalo M, et al. Low-back pain in adolescent athletes. Med Sci Sports Exerc 1996;28:165-70.

6 Gurd DP. Back pain in the young athlete. Sports Med Arthrosc Rev 2011;19:7-16.

7 Müller J, Müller S, Stoll J, et al. Back pain prevalence in adolescent athletes. Scand J Med Sci Sports 2017;27:448-54.

8 Micheli LJ, Wood R. Back pain in young athletes. Arch Pediatr Adolesc Med 1995;149:15-18.

9 Eriksson K, Németh G, Eriksson E. Low back pain in elite crosscountry skiers. A retrospective epidemiological study. Scand J Med Sci Sports 1996;6:31-5.

10 Sassmannshausen G, Smith BG. Back pain in the young athlete. Clin Sports Med 2002;21:121-32.

11 Swärd L, Hellstrom M, Jacobsson B, et al. Back pain and radiologic changes in the thoraco-lumbar spine of athletes. Spine 1990;15:124-9.

12 Razeghi M, Batt ME. Foot type classification: a critical review of current methods. Gait Posture 2002;15:282-91.

13 Murphy DF, Connolly DAJ, Beynnon BD. Risk factors for lower extremity injury: a review of the literature. Br J Sports Med 2003;37:13-29.
14 Yates B, White S. The incidence and risk factors in the development of medial tibial stress syndrome among naval recruits. Am J Sports Med 2004;32:772-80.

15 Bennett JE, Reinking MF, Pluemer B, et al. Factors contributing to the development of medial tibial stress syndrome in high school runners. J Orthop Sports Phys Ther 2001;31:504-10.

16 Simon TD, Bublitz C, Hambidge SJ. Emergency department visits among pediatric patients for sports-related injury: basic epidemiology and impact of race/ethnicity and insurance status. Pediatr Emerg Care 2006;22:309-15.

17 Kujala UM, Kvist M, Osterman K. Knee injuries in athletes. Review of exertion injuries and retrospective study of outpatient sports clinic material. Sports Med 1986;3:447-60.

18 Hall R, Barber Foss K, Hewett TE, et al. Sport specialization's association with an increased risk of developing anterior knee pain in adolescent female athletes. $J$ Sport Rehabil 2015;24:31-5.

19 Bergeron MF, Mountjoy M, Armstrong N, et al. International olympic committee consensus statement on youth athletic development. Br J Sports Med 2015;49:843-51.

20 Myer GD, Sugimoto D, Thomas S, et al. The influence of age on the effectiveness of neuromuscular training to reduce anterior cruciate ligament injury in female athletes: a meta-analysis. Am J Sports Med 2013;41:203-15.

21 Sugimoto D, Myer GD, Foss KDB, et al. Specific exercise effects of preventive neuromuscular training intervention on anterior cruciate ligament injury risk reduction in young females: meta-analysis and subgroup analysis. Br J Sports Med 2015;49:282-9.

22 Sugimoto D, Myer GD, Barber Foss KD, et al. Critical components of neuromuscular training to reduce $A C L$ injury risk in female athletes: meta-regression analysis. $\mathrm{Br} \mathrm{J}$ Sports Med 2016;50:1259-66.

23 Nakajima H. Orthopaedic medical checkup. Rinshou Sports Igaku 1985;2:735-40.

24 Kobayashi A, Kobayashi T, Kato K, et al. Diagnosis of radiographically occult lumbar spondylolysis in young athletes by magnetic resonance imaging. Am J Sports Med 2013;41:169-76.

25 Beighton P, Solomon L, Soskolne CL. Articular mobility in an African population. Ann Rheum Dis 1973;32:413-8.

26 Frost M, Stuckey S, Smalley LA, et al. Reliability of measuring trunk motions in centimeters. Phys Ther 1982;62:1431-7.

27 Schneider-Kolsky ME, Hoving JL, Warren P, et al. A comparison between clinical assessment and magnetic resonance imaging of acute hamstring injuries. Am J Sports Med 2006;34:1008-15.

28 Lee KM, Chung CY, Kwon DG, et al. Reliability of physical examination in the measurement of hip flexion contracture and correlation with gait parameters in cerebral palsy. J Bone Joint Surg Am 2011:93:150-8.

29 Peeler J, Anderson JE. Reliability of the Ely's test for assessing rectus femoris muscle flexibility and joint range of motion. $J$ Orthop Res 2008;26:793-9.

30 Biedert RM, Warnke K. Correlation between the $\mathrm{Q}$ angle and the patella position: a clinical and axial computed tomography evaluation. Arch Orthop Trauma Surg 2001;121:346-9.

31 Saltzman CL, Nawoczenski DA, Talbot KD. Measurement of the medial longitudinal arch. Arch Phys Med Rehabil 1995;76:45-9.

32 Roth S, Roth A, Jotanovic Z, et al. Navicular index for differentiation of flatfoot from normal foot. Int Orthop 2013;37:1107-12.

33 Cheng AL, Merlo JA, Hunt D, et al. Are hip physical examination findings predictive of future lower body injury rates in elite adolescent female soccer athletes at minimum 5-year follow-up? J Sport Rehabil 2019;29:476-82

34 Jonasson P, Halldin K, Karlsson J, et al. Prevalence of joint-related pain in the extremities and spine in five groups of top athletes. Knee Surg Sports Traumatol Arthrosc 2011;19:1540-6.

35 Orchard JJ, Orchard JW, La Gerche A, et al. Audit of a cardiac screening policy for elite Australian cricketers. J Sci Med Sport 2020;23:541-7.

36 Perrin T, Trachsel LD, Schneiter S, et al. Prevalence of abnormal electrocardiograms in Swiss elite athletes detected with modern screening criteria. Swiss Med Wkly 2016;146:w14376.

37 Le V-V, Wheeler MT, Mandic S, et al. Addition of the electrocardiogram to the preparticipation examination of college athletes. Clin J Sport Med 2010;20:98-105.

38 Valle X, Malliaropoulos N, Párraga Botero JD, et al. Hamstring and other thigh injuries in children and young athletes. Scand $\mathrm{J}$ Med Sci Sports 2018;28:2630-7.

39 Rossi M, Pasanen K, Kokko S, et al. Low back and neck and shoulder pain in members and non-members of adolescents' sports clubs: the Finnish health promoting sports Club (FHPSC) study. BMC Musculoskelet Disord 2016;17:263. 
40 Vikat A, Rimpelä M, Salminen JJ, et al. Neck or shoulder pain and low back pain in Finnish adolescents. Scand J Public Health 2000;28:164-73.

41 Louw QA, Manilall J, Grimmer KA. Epidemiology of knee injuries among adolescents: a systematic review. Br J Sports Med 2008;42:2-10.

42 Ingram JG, Fields SK, Yard EE, et al. Epidemiology of knee injuries among boys and girls in US high school athletics. Am J Sports Med 2008;36:1116-22.

43 DiFiori JP, Benjamin HJ, Brenner JS, et al. Overuse injuries and burnout in youth sports: a position statement from the American medical society for sports medicine. Br J Sports Med 2014;48:287-8

44 Jayanthi N, Pinkham C, Dugas L, et al. Sports specialization in young athletes: evidence-based recommendations. Sports Health 2013;5:251-7.

45 Hall R, Barber Foss K, Hewett TE, et al. Sport specialization's association with an increased risk of developing anterior knee pain in adolescent female athletes. J Sport Rehabil 2015;24:31-5.

46 Wiersma LD. Risks and benefits of youth sport specialization: perspectives and recommendations. Pediatr Exerc Sci 2000;12:13-22

47 Twomey $\mathrm{D}$, Finch $\mathrm{C}$, Roediger $\mathrm{E}$, et al. Preventing lower limb injuries: is the latest evidence being translated into the football field? $J \mathrm{Sci}$ Med Sport 2009;12:452-6.

48 Carey TS, Garrett J, Jackman A, et al. The outcomes and costs of care for acute low back pain among patients seen by primary care practitioners, chiropractors, and orthopedic surgeons. The North Carolina back pain project. N Engl J Med 1995;333:913-7.

49 Tall RL, DeVault W. Spinal injury in sport: epidemiologic considerations. Clin Sports Med 1993;12:441-8.

50 Bono CM. Low-back pain in athletes. J Bone Joint Surg Am 2004;86:382-96.

51 Purcell L, Micheli L. Low back pain in young athletes. Sports Health 2009;1:212-22.

52 Sakai T, Tezuka F, Yamashita K, et al. Conservative treatment for bony healing in pediatric lumbar Spondylolysis. Spine 2017;42:E716-20.
53 Fong DT-P, Hong Y, Chan L-K, et al. A systematic review on ankle injury and ankle sprain in sports. Sports Med 2007;37:73-94.

54 DiGiovanni BF, Partal G, Baumhauer JF. Acute ankle injury and chronic lateral instability in the athlete. Clin Sports Med 2004;23:1-19.

55 Walther M, Kriegelstein S, Altenberger S, et al. [Lateral ligament injuries of the ankle joint]. Unfallchirurg 2013;116:776-80.

56 Herzog MM, Kerr ZY, Marshall SW, et al. Epidemiology of ankle Sprains and chronic ankle instability. J Athl Train 2019;54:603-10.

57 Clifton DR, Koldenhoven RM, Hertel J, et al. Epidemiological patterns of ankle Sprains in youth, high school, and college football. Am J Sports Med 2017;45:417-25.

58 Hiller CE, Nightingale EJ, Raymond J, et al. Prevalence and impact of chronic musculoskeletal ankle disorders in the community. Arch Phys Med Rehabil 2012;93:1801-7.

59 Hubbard-Turner T. Lack of medical treatment from a medical professional after an ankle sprain. J Athl Train 2019;54:671-5.

60 Raske A, Norlin R. Injury incidence and prevalence among elite weight and power lifters. Am J Sports Med 2002;30:248-56.

61 Kujala UM, Taimela S, Salminen JJ, et al. Baseline anthropometry, flexibility and strength characteristics and future low-back pain in adolescent athletes and nonathletes. Scand J Med Sci Sports 1994;4:200-5.

62 Feldman DE, Shrier I, Rossignol M, et al. Risk factors for the development of low back pain in adolescence. Am J Epidemio 2001;154:30-6.

63 Korpelainen R, Orava S, Karpakka J, et al. Risk factors for recurrent stress fractures in athletes. Am J Sports Med 2001;29:304-10.

64 Burns J, Keenan A-M, Redmond A. Foot type and overuse injury in triathletes. J Am Podiatr Med Assoc 2005;95:235-41.

65 Adirim TA, Cheng TL. Overview of injuries in the young athlete. Sports Med 2003;33:75-81.

66 Bromley SJ, Drew MK, Talpey S, et al. A systematic review of prospective epidemiological research into injury and illness in Olympic combat sport. Br J Sports Med 2018;52:8-16.

67 Menz HB, Munteanu SE. Validity of 3 clinical techniques for the measurement of static foot posture in older people. $J$ Orthop Sports Phys Ther 2005;35:479-86. 